generally held, when the amount of fluid threatened suffocation, but also, as in the case under consideration, when the powers of life are manifestly giving way. He also urged the insertion of the drainage-tube in similar cases; for although in this instance recovery did not take place, the good effects of this plan of treatment were sufficiently manifest. Dr. Fincham pointed out that these good effects were twofold. In the first place, it prevents the reaccumulation of pus, and so does away with the necessity of repeated tappings; and, secondly, a most important point, by its favouring the escape of pus as soon as it is secreted no decomposition can take place within the cavity of the chest, and thus absorption of poisonous gases is rendered impossible. In the present case the change in the character of the discharge after the insertion of the drainagetube was most marked: the pus became healthy and discharged freely, and the fetor ceased; whereas previously, although the silver canula was constantly worn, and the chest frequently syringed out with a weak solution of Condy's fluid, only temporary good was effected. It was hoped that the hyposulphite of soda, as advocated by Dr. Polli, of Milan, as an antidote to septic poisoning, might have proved of service; no advantage, however, appeared to have resulted from its use

\section{WEST LONDON HOSPITAL.}

YBRY LARGE ANEURISM OF THE ABDOMINAL AORTA. (Under the care of Dr. Maudshey.)

For the notes of the following extremely interesting case we are indebted to Mr. G. Jackson, house-surgeon to the hospital. The tumour was distinctly made out during life, but its nature was doubtful until death revealed it.

J. B-, aged forty-three, admitted February 12th, 1865. Had been a soldier, and had enjoyed good health up to about twelve months ago, since which time he has suffered from pain in the left side, extending down the left leg, which has also had a sense of numbness in it, and he has walked lame on that leg. He has drunk hard, been in hot climates, smoked much, and had syphilis.

About a fortnight before admission, when first seen, he had pleurisy on the left side; in about a week the symptoms ceased, and then a rapid swelling of the abdomen suddenly took place, its surface being tensely cedematous, especially over the left half, which was more prominent. The left leg also became generally and largely œdematous. His face was blanched and exceedingly anxious. He suffered from constipation. He was not emaciated, but his general state was low.

Feb. 2lst. - The cedema of the abdomen having greatly subsided, a more or less defined tumour was noticed in the left lumbar region, extending from the last rib to the crest of the ilium. No pulsation was felt, or bruit heard.

As a rule he did not complain of much pain; once or twice he said that he feit a darting pain in the region of the tumour. Urine acid, sp. gr. 1028 ; lithates abundant; no albumen or casts.

March 3rd.-Died this evening, having gradually sunk from the time of admission.

Autopsy, fifty hours after death.-Old and firm pleural adhesions on both sides, extending over almost the entire surface of both lungs, which were much congested, the lower lobe of left lung being hepatized. The valves of the heart were healthy; but the left ventricle was greatly hypertrophied. A large mass filled up the whole of the left side of the abdominal cavity, and to it the descending colon was adherent in its whole course; it extended from the lower surface of the diaphragm down to the left iliac fossa, the upper part of the hollow of which formed part of its bed. It was impossible to separate it from the posterior wall of the abdomen, to which it was matted. There was extensive caries of the left side of the lumbar vertebræ, and of the last rib, which was completely ulcerated through, and of the crest of the left iliac bone on its inner and upper surface. The tumour was an immense aneurism of the abdominal aorta, filled up with multitudinous layers of fibrin, more or less firm, and with a large quantity of coagula. The left kidney was flattened, atrophied, fatty, and glued in the wall of the sac. The walls of the sac were very thin in some places, and closely adherent in others to the bodies of the vertebra. The upper limit of the aneurism was about the spot at which the thoracic becomes the abdominal aorta; the lower limit thereof was immediately after the entrance of the left common iliac artery. The thoracic aorta was adherent to the walls of the aneurism for about two inches before it entered the sac.
The great difficulty in the diagnosis of tumours is well illus trated by this case. No bruit or expansion being noted all that could be said with certainty was, that a large tumour of some kind filled up the left half of the abdomen, and pressed upon the left iliac vein so as to cause cedema of the parts, which passed their blood into that channel.

It is worthy of remark also that a man with so vast a mass of mortal mischief in his abdomen should have apparently suffered so little as to be able to continue his work as a gardener, as this patient did until obliged to give up by reason of an attack of pleurisy.

The treatment in this case at the time it came under obsesvation was, of course, only palliative. Whether, if it had been detected earlier, pressure might have been applied, as is said to have been done successfully in one case, must remain very doubtful.

\section{ST. THOMAS'S HOSPITAL.}

TRAUMATIC ANEURISM OF THE FACIAL ARTERY, CURED BY IIGATURE OF THE VESSEL.

(Under the care of Mr. LE Gros Clark.)

AN engine-fitter, aged twenty-six, was admitted into this hospital on April 10th, 1865. He is a temperate man, of good constitution. About five weeks since he received a kick from a man on the left side of the lower jaw. There was no external wound. In a few minutes the injured part became very tumid, and he could feel the swelling throb. The injury was not treated in any way; and the patient stated that in the course of a fortnight the swelling had nearly subsided, but the pulsa. tion continued. Subsequently suppuration occurred, and pus and clotted blood escaped through a spontaneous opening in the mouth, near the molar teeth. Pulsation continued, and the wound closed. It was then reopened, and a considerable quantity of arterial blood was lost on several occasions. When admitted, there was a pulsating tumour in front of the masseter muscle, and the man was beginning to show the effects of the loss of blood. As pressure on the facial artery arrested the pulsation, a ligature was placed on this vessel as it crosses the ramus of the jaw. There was no return of pulsation, and the patient left the hospital in a fortnight, well.

Remarks. - The blow ruptured the facial artery. A diffused aneurism was the consequence. This became, subsequently, by the absorption of the clot, a circumscribed false aneurism. In this suppuration took place, and the lancet only made matters worse by establishing an exit for the blood. The ligature was the remedy indicated, and its application was successful-an epitome of what is seen in the femoral and other large arteries.

\section{attevical Socretties.}

\section{ROYAL MEDICAL AND CHIRURGICAL SOCIETY.}

TUESDAY, JUNE 27TH, 1865.

Dr. Alderson, F.P.S., Presidert.

\section{A SECOND SERIES OF FIFTY CASES OF OVARIOTOMY; WITH REMARKS ON THE SELECTION OF CASES FOR THE OPERATION. \\ BY T. S. WELLS, F.R.C.S., STBGBON TO HER MAJESTX'S HOUSEROLD, AND TO THJ SAMARITAY HOSPITAL.}

THE author has constructed a table showing at a glance the result of the fifty operations; the recoveries being to the deaths in the proportion of two to one. The most favourable age for the operation appears to be before twenty-five or above forty. The conjugal conditions of the patients seem to have little effect on the result. Hospital cases have been more successfu! than private cases. The result of the operation depends but little on the season of the year in which it is performed. Adhesions of the tumour to the abdominal wall and intestines are of little importance; adhesions to the bladder, iliac vessels, ureters, or rectum are very unfavourable. A short pedicle is also very unfavourable. There is no doubt that the cases where the stump of the pedicle can be kept external to the peritoneum are much more uniformly successful than those in which the stump is allowed to sink into the abdominal cavity. I 2 